\title{
OPERATIONAL PROPERTIES OF THE CERMET ELECTRO-SPARK COATINGS AFTER LASER TREATMENT - TECHNOLOGY AND APPLICATION
}

doi: $\quad 10.2478 /$ czoto-2019-0102

Date of submission of the article to the Editor: 09/11/2018

Date of acceptance of the article by the Editor: 28/12/2018

Norbert Radek ${ }^{1}$ - orcid id: 0000-0002-1587-1074

Jacek Pietraszek ${ }^{2}$ - orcid id: 0000-0003-2851-1606

Janusz Konstanty ${ }^{3}$ - orcid id: 0000-0001-6761-9623

${ }^{1}$ Kielce University of Technology, Poland, norrad@tu.kielce.pl

${ }^{2}$ Cracow University of Technology, Poland

${ }^{3} \mathrm{AGH}-$ University of Science and Technology, Poland

\begin{abstract}
The paper is concerned with determining the influence of the laser treatment process on the properties of electro-spark coatings. The properties of the coatings after laser treatment were assessed based on following methods: microstructure and X-ray diffraction analysis, adhesion tests, roughness measurement, hardness tests, tribological properties and application tests. The tests were carried out on WC-Co coating (the anode) obtained by electro-spark deposition over carbon steel C45 (the cathode) and molten with a laser beam. The coatings were deposited by means of the EIL-8A and they were laser treated with the Nd:YAG. The tests show that the laser-treated electro-spark deposited WC-Co coatings are characterized by lower hardness, higher seizure resistance, roughness and adhesion. The laser treatment process causes the homogenization of the chemical composition, the structure refinement and the healing of microcracks and pores of the electro-spark deposited coatings. Laser treated electro-spark deposited coatings are likely to be applied in sliding friction pairs and as protective coatings.
\end{abstract}

Keywords: electro-spark deposition, laser treatment, properties, coating

\section{INTRODUCTION}

Sintered carbides are cermets consisting of $70 \div 96 \%$ refractory metal (e.g. tungsten, tantalum, niobium) carbides and a binding matrix that is usually cobalt, sometimes molybdenum or nickel, and occasionally iron. Presently, sintered carbides are a very popular material for making cutting tool edges, especially in turning and milling operations (FANAR, 2018).

Depending on occurrence forms of oxides, carbides and nitrides may be very advantageous, in the form of a sintered carbide improves tool life, sometimes oxide layer improves the biocompatibility, limits the corrosion development etc. In the case of the cobalt, molybdenum, iron, nickel oxide or carbide formation may affect on the 
material functional properties (hardness, roughness, corrosion resistance) (KlimeckaTatar et al., 2014). The use of ceramic tool materials is low when compared with sintered carbides, yet it tends to grow continually. It is estimated that approx. $5 \%$ of cutting tool edges are made of this material type. The substances most widely used to manufacture ceramic tool materials include the following:

- single-phase alumina $\mathrm{Al}_{2} \mathrm{O}_{3}$,

- silicon nitride $\mathrm{Si}_{3} \mathrm{~N}_{4}$,

- multi-phase $\mathrm{Al}_{2} \mathrm{O}_{3}$ and $\mathrm{Si}_{3} \mathrm{~N}_{4}$ mixtures with hard carbides, nitrides and oxides.

An interesting option is provided by the manufacture of anti-wear cermetal coatings that are electro-spark alloying (ESA) using electrodes obtained by the Pulse Plasma Sintering method (PPS) of nanostructural powders. Super-hard coatings can be deposited on the edges of cutting tools, such as, e.g. lathe tools, milling cutters, pinion cutters or taps. It is supposed that the coatings of concern can be successfully applied to those machine components that operate under extreme conditions, including high abrasive wear or impact loads.

Electro-spark deposited (ESD) coatings have some disadvantages but these can be easily eliminated. One of the methods is laser beam processing (LBP); a laser beam is used for surface polishing, surface geometry formation, surface sealing or for homogenizing the chemical composition of the deposited coatings (Radek et al., 2008; Radek and Konstanty, 2012; Pietraszek et al., 2013; Radek et al., 2014).

It is envisaged that the advantages of laser-treated electro-spark coatings will include: lower roughness, lower porosity, better adhesion to the substrate, higher wear and seizure resistance, higher fatigue strength due to the occurrence of compressive stresses on the surface, higher resistance to corrosion, surface shaping.

\section{METHODOLOGY}

The WC-Co coatings were produced by electro-spark deposition. Cylindrical electrospark electrodes, $5 \mathrm{~mm}$ in diameter and $10 \mathrm{~mm}$ in height were used to deposit the coatings on C45 mild steel surface. Electrodes containing 95\% WC and 5\% Co, were produced using by the Pulse Plasma Sintering method. The main characteristics of powders used in this work are included in Table 1.

Table 1

Powders used to manufacture electrodes

\begin{tabular}{|l|l|l|}
\hline Powder & Particle size $[\mu \mathrm{m}]$ & Producer \\
\hline WC & $\sim 0.2^{*}$ & OMG (USA) \\
\hline Co & $\sim 0.4^{*}$ & Umicore (Belgium) \\
\hline
\end{tabular}

*measured using Fisher Sub-Sieve Sizer

The coatings were deposited in the argon atmosphere with the use of an EIL-8A pulse generator for triggering spark gaps, with manual electrode displacement. The following parameters were established in compliance with the manufacturer's guidelines and previous experience of the authors: voltage $U=230 \mathrm{~V}$, capacitor volume $\mathrm{C}=300 \mu \mathrm{F}$, current intensity I $=2.2 \mathrm{~A}$, deposition time $\tau=2 \mathrm{~min} / \mathrm{cm}^{2}$.

The coatings were subjected to laser treatment at the Centre for Laser Technology of Metals. The laser used was a BLS $720 \mathrm{Nd}$ :YAG laser capable of generating $150 \mathrm{~W}$ 
maximum average power, operating in the pulse mode, manufactured by Basel Lasertechnik. The laser treatment was performed in the ambient air atmosphere. The tests used a focusing head. The $\mathrm{TEM}_{00}$ beam defined the radiation energy distribution. The parameters used were as follows: spot diameter $\mathrm{d}=0.7 \mathrm{~mm}$; laser power $\mathrm{P}=20 \mathrm{~W}$; specimen movement rate $\mathrm{v}=250 \mathrm{~mm} / \mathrm{min}$; nozzle-workpiece distance $\Delta \mathrm{l}=1 \mathrm{~mm}$; pulse duration $t_{i}=0.4 \mathrm{~ms}$; pulse repetition frequency $\mathrm{f}=50 \mathrm{~Hz}$; beam shift jump $S=0.4 \mathrm{~mm}$.

\section{RESULTS OF INVESTIGATIONS AND DISCUSSION}

\subsection{Microstructure and X-ray diffraction analysis}

A microstructure analysis was conducted for WC-Co coatings before and after laser treatment using a scanning electron microscope Quanta 3D FEG (SEM/FIB). In Fig. 1 selected view of the surface microstructure of an electro-spark alloying WC-Co coating is illustrated. From results obtained, it is clear that the thickness of the obtained layers was 30 to $40 \mu \mathrm{m}$, whereas the heat affected zone (HAZ) ranged approximately 15 to $20 \mu \mathrm{m}$ into the substrate. In this micrograph (Fig. 1) there is a clear boundary between the coating and the substrate, where pores within microcracks are observed. The electro-spark alloying WC-Co coatings was modified via laser beam solidify, which caused their composition changes. The laser treatment leads to the homogenizing of the coating chemical composition, structure refinement, and crystallization of phases supersaturated due to the occurrence of temperature gradients and high cooling rate.

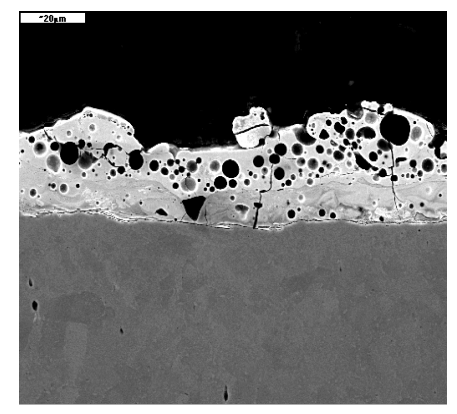

Fig. 1. WC-Co coating microstructure after electro-spark alloying

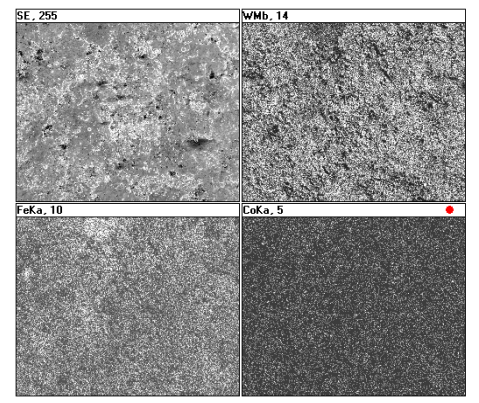

Fig. 2. Surface distribution of elements in the WC-Co coating

The laser-modified outer layer does not possess microcracks or pores (Fig. 3). There was no discontinuity of the coating-substrate boundary. The thickness of the lasertreated WC-Co coatings was in the range 40 to $50 \mu \mathrm{m}$. Moreover, the Heat-Affected Zone (HAZ) was in the range of 30 to $40 \mu \mathrm{m}$, and the content of carbon in the zone was higher.

Sample analyzes of surface distribution of elements in the WC-Co coatings before and after laser treatment are presented in Figures 2 and 4 . In the figures presented, the amount of the element is proportional to the brightness of the image in the analyzed place. The electro-spark coating (Fig. 2) is mainly composed of tungsten and iron atoms (a large number of light fields) and a small number of cobalt atoms.

As a result of remelting the laser of coating (Fig. 4) there was a locally high intensity of W and Fe atoms. Large groups of tungsten atoms occurred on the sides of 
the resulting trace of melting, while the high intensity of bright Fe fields formed in its center.

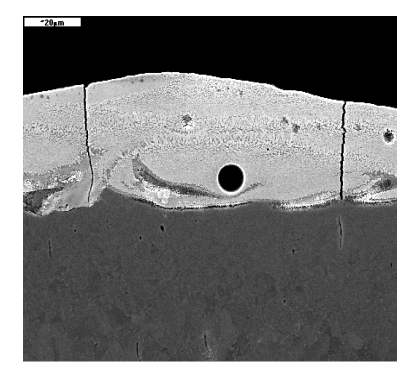

Fig. 3. Microstructure in the electro-spark alloying WC-Co coating after laser treatment

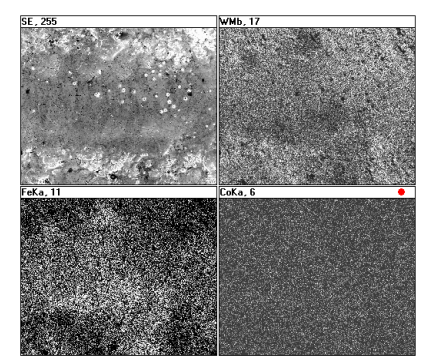

Fig. 4. Surface distribution of elements in the WC-Co coating after laser treatment

A Philips PW 1830 X-ray diffractometer with CuK $\alpha$ radiation, operating at $40 \mathrm{kV}$ and $30 \mathrm{~mA}$, was used for phase(s) identification. The analysis of the phase composition of the WC-Co coating revealed that the surface layer of the coating consisted mainly of $\mathrm{WC}$ and $\mathrm{W}_{2} \mathrm{C}$ before and after laser treatment. Laser treatment caused the WC-Co coating to melt into the substrate, resulting in $\mathrm{Fe}_{3} \mathrm{~W}_{3} \mathrm{C}$ and Fe phases.

\subsection{Adhesion tests}

Scratch adhesion testing was conducted to assess the adhesion of the WC-Co coatings to the C45 grade steel substrate using the CSEM Revetest scratch tester. The tests consisted of scratching a coated, or coated and laser treated, sample with a diamond stylus of $200 \mu \mathrm{m}$ tip radius at a table speed of $9.77 \mathrm{~mm} / \mathrm{min}$ under step-wise increasing normal stylus load of $103.2 \mathrm{~N} / \mathrm{min}$. Coating removal, and hence the critical stylus load, was identified through a combination of optical examination, changes in the tangential force and acoustic emission. The results are presented in Table 2.

Table 2

Results of scratch adhesion tests

\begin{tabular}{|l|l|l|l|l|}
\hline \multirow{2}{*}{ Coating condition } & \multicolumn{3}{|c|}{ Critical stylus load [N] } & \multirow{3}{*}{ Mean value $^{\dagger}[\mathbf{N}]$} \\
\cline { 2 - 4 } & 1 & 2 & 3 & \\
\hline As-deposited & 7.89 & 8.16 & 6.53 & $7.53 \pm 0.87$ \\
\hline Laser treated & 9.92 & 11.21 & 10.34 & $10.49 \pm 0.66$ \\
\hline
\end{tabular}

${ }^{\dagger}$ scatter intervals estimated at $90 \%$ confidence level

From the obtained data it becomes evident that due to laser treatment it is possible to markedly improve adhesion of the WC-Co coating to the C45 steel substrate. In addition, the low scatter of critical stylus loads indicate that the laser treatment presumably eliminate voids present at the coating/substrate interface.

\subsection{Tribological studies}

Seizure resistance tests were carried out using the T-09 tribotester, in which the friction pair consisted of a cylinder and two prisms (Fig. 5). The surfaces tested were WC-Co coatings and C45 steel before and after laser processing. The roller had a diameter of $6.3 \mathrm{~mm}$ was made of carbon steel. The tests were conducted for three kinematic pairs for each material variant, so it was possible to average the data. The 
experiment involved submerging the specimens in pure lubricant. In this case paraffin oil was used. This oil guranntee constant lubricanting ablility in each carried out test. It's difficult to compare results, when lubricant oil with additional oilness improvers is applied. Some of improvers are biodegradal and chaning oil properties even during short time of storage. To keeping stable and comparable results parafin oil is common use in laboratory's wearing tests. In Fig. 6 an average seizure loads before and after laser processing is presented. It is clear that the laser processing operation caused an increase in the load force and, accordingly, seizure of the electro-spark deposited coatings and C45 steel.

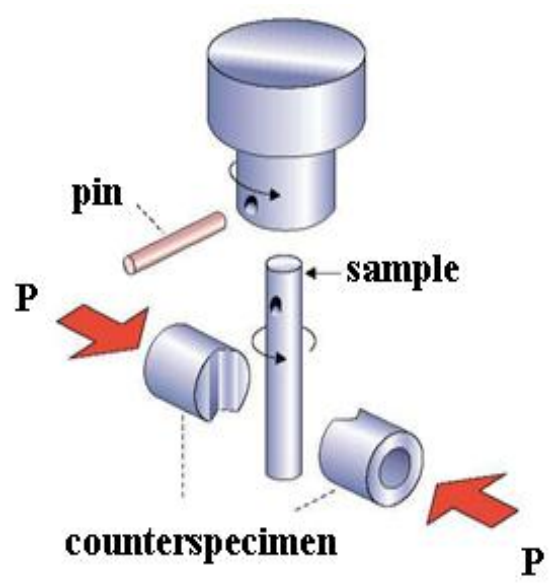

Fig. 5. Diagram of friction pair in a Falex T-09-type tribological tester

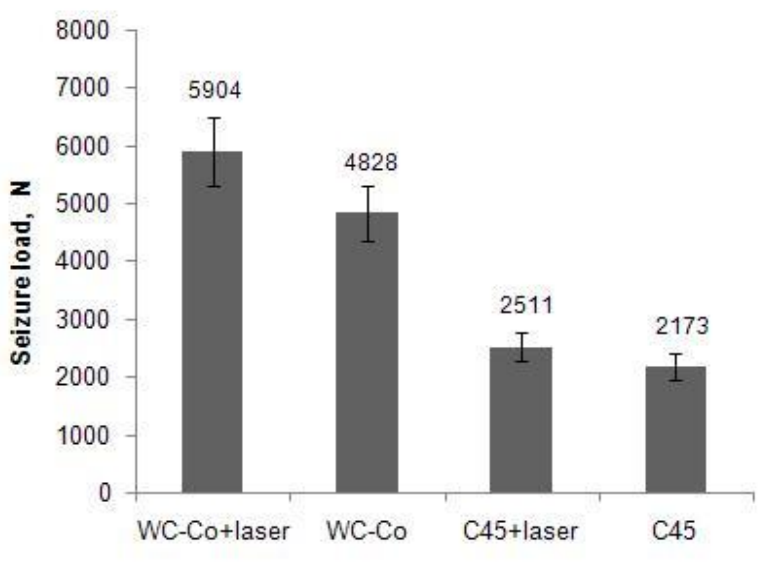

Fig. 6. Average values of seizure load

\subsection{Microhardness testing}

The microhardness tests were carried out with a Vickers indentor, under a load of $0.4 \mathrm{~N}$, on polished cross-sections at three different locations, i.e. in the coating, in the heat affected zone (HAZ) located close to the coating, and in the substrate at a certain distance from the coating. An uncoated substrate material was also tested.

Table 3

Results of scratch adhesion tests

\begin{tabular}{|l|c|c|c|}
\hline \multirow{2}{*}{ Coating condition } & \multicolumn{3}{|c|}{ HV0.4 $^{\dagger}$} \\
\cline { 2 - 4 } & Coating & HAZ & Substrate \\
\hline As-deposited & $1245 \pm 46$ & $421 \pm 28$ & $142 \pm 5$ \\
\hline Laser treated & $1176 \pm 51$ & $407 \pm 33$ & $141 \pm 6$ \\
\hline
\end{tabular}

${ }^{\dagger}$ scatter intervals estimated at $90 \%$ confidence level

The hardness test results presented in Table 3 indicate minor decrease in microhardness of both the coating and HAZ after laser treatment, whereas the steel substrate remains unaffected. It was observed a slight decrease, about $6 \%$, in the electro-spark alloying coatings hardness after applied laser treatment. This fall may cause an improvement of their elastic properties, which is important during operation under big loads, e.g.: drilling tools in the extractive industry, or press elements in building ceramics. 


\subsection{Measurements of the roughness}

The roughness of the WC-Co coatings was assessed quantitatively using the Talysurf $\mathrm{CCl}$ optical profiler. Roughness profiles are routinely measured by dragging a stylus along the laser beam path whereas the maximum values of the arithmetic average departure from the plain surface are reported to occur in the perpendicular direction. Therefore in this study an average value of $R a$ was calculated for each coating from the readings taken on evenly divided sampling lengths running parallel to the electrode/laser beam motion path and on similar lengths at $90^{\circ}$. It was found that the employed surface treatments increased the average roughness value $(R a)$ from $0.39 \div 0.41 \mu \mathrm{m}$ for the C45 steel substrate up to $1.35 \div 2.01 \mu \mathrm{m}$ and $3.15 \div 4.46 \mu \mathrm{m}$ for the WC-Co coatings in as-deposited and laser treated condition, respectively.

It is evident from the measurements that there is an increase in roughness of the WC-Co coatings after laser treatment. The higher roughness resulted from the tensile forces acting on the surface, and accordingly, the motion of the liquid metal. A nonuniform distribution of temperature in a laser beam (mod $\mathrm{TEM}_{00}$ ) caused the nonuniformity of the surface profile after solidification, which, to some extent, reflects the distribution of energy in the melted zone. If pulse laser treatment is applied, it is assumed that the main factor affecting the surface profile after solidification is the pressure of vapor causing the disposal of the material from the central zone and the production of characteristic flashes on the boundary between the melted and unmelted zones.

\subsection{Applications of cermet coatings}

As part of practical applications of WC-Co coatings, regeneration of used gas bottle markers was performed. The markers are made of N11 tool steel and are used in the company Milmet S.A. Only the working edges of markers were strengthened. The markers regeneration process has been divided into two series:

- the first series is the regeneration of markers by applying cermet coatings,

- the second series is the regeneration of markers by applying cermet coatings and their laser processing.

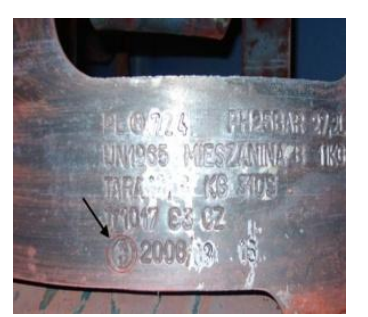

Fig. 7. The flange of a gas cylinder with a permanent mark

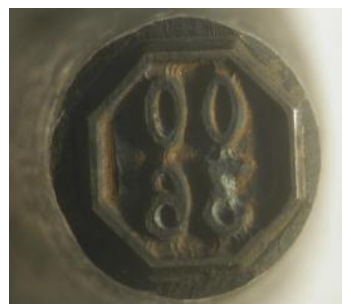

Fig. 8. Worn marker intended for regeneration

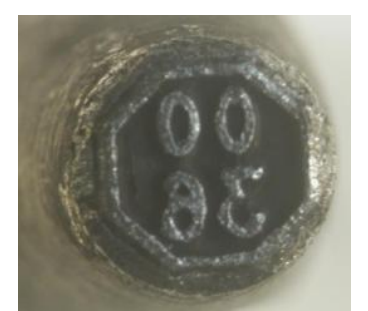

Fig. 9. Marker with WC-Co electro-spark coating

Company Milmet S.A. deals in the production of gas cylinders for technical and hydrocarbon gases. In terms of services, it also offers renovation of used cylinders. During the renovation of used cylinders, permanent marks are applied to the cylinder flange (Fig. 7). Figure 8 shows a worn marker for regeneration. In contrast, Figure 9 shows the marker with the WC-Co electro-spark coating applied.

As part of cooperation with Milmet S.A. a technological process for the regeneration of markers with the determination of individual operations has been 
developed. At present, markers coated with the aforementioned cermet coatings before and after laser treatment are tested under real working conditions.

\section{CONCLUSION}

After the carried out investigations, the following conclusions can be drawn:

- The electro-spark alloying coating outer surface layer could be modified via focused laser beam, which has significant impact on the coating surface properties.

- The laser treatment causes that the electro-spark alloying coatings melt and then solidify. The refinement of structure and disappearance of microcracks were noticed.

- The subsurface layer of the WC-Co coating before and after laser treatment consists of mainly $\mathrm{WC}$ and $\mathrm{W}_{2} \mathrm{C}$.

- Laser treatment caused a $28 \%$ increase in the adhesion of the electro-spark alloying WC-Co coatings.

- After laser processing significant load force can be applied. The material seizure of the WC-Co coatings modified after laser treatment was increase about $18 \%$.

- The roughness of ESD coatings have lower values when compared with those characterising coatings after laser treatment.

- Laser treatment of ESD WC-Cu coatings decreases its microhardness by $6 \%$.

- Electro-spark alloying WC-Co coatings can be used to regenerate tools.

Similar methods of surface modification may be useful in other areas like e.g. anticorrosion protection (Wlodarczyk et al., 2011; Pawlowska et al., 2017), sintering (Pieczonka et al., 2012), biomaterials, strengthening the wear resistance (Weglowski and Osocha, 2009; Ulewicz et al., 2014; Osocha, 2018), what may be a vital issue in the rolling mill (Sygut et al., 2016), woodworking industry (Ulewicz, 2016), cast iron foundry (Ulewicz et al., 2013) and even in biotechnological experiments with aggressive solvents (Skrzypczak-Pietraszek, 2016; Skrzypczak-Pietraszek et al., 2017; Skrzypczak-Pietraszek et al., 2018). Extreme conditions requiring a surface preparation with special coating may be met in heavy-duty machines (Domagala et al., 2018a; Domagala et al., 2018b) and in high-energy physics infrastructure (Singh et al., 2017). Microscopy inspection of such coatings may be very inspired for the image analysis development (Gadek-Moszczak, 2017).

\section{REFERENCES}

Domagala, M., Momein, H., Domagala-Fabis, J., Filo, G., Kwiatkowski, D., $2018 a$. Simulation of Cavitation Erosion in a Hydraulic Valve. Mater. Res. Proc., 5, 1-6.

Domagala, M., Momeni, H., Domagala-Fabis, J., Filo, G., Krawczyk, M., 2018b, Simulation of Particle Erosion in a Hydraulic Valve. Mater. Res. Proc., 5, 17-24.

Dudek, A., Wlodarczyk, R., 2010. Structure and properties of bioceramics layers Used for implant coatings. Solid State Phenom., 165, 31-36.

FANAR S.A. - production of cutting tools. http://www.fanar.pl (date 20.11.2018).

Gadek-Moszczak, A., 2017. History of stereology. Image Anal. Stereol., 36, 151-152.

Klimecka-Tatar, D., Pawlowska, G., Orlicki, R., Zaikov, G.E., 2014. Corrosion characteristics in alkaline, and ringer solution of Fe68-xCoxZr10Mo5W2B15 metalic glasses. J. Balk. Tribol. Assoc., 20(1), 124-130.

Osocha, P., 2018. Calculation of residual life for P91 material based on creep rate and time to rupture. Mater. Res. Proc., 5, 177-182. 
Pawlowska, G., Klimecka-Tatar, D., Radomska, K., 2017. The effect of bio-tolerated binder content on the corrosive behavior of RE-M-B in magnetic composites in sulphite solutions. Ochr. Przed Koroz., 60, 372-375.

Pieczonka, T., Kazior, J., Szewczyk-Nykiel, A., Hebda, M., Nykiel, M., 2012. Effect of atmosphere on sintering of Alumix 431D powder. Powder Metall., 55, 354-360.

Pietraszek, J., Radek, N., Bartkowiak, K., 2013. Advanced statistical refinement of surface layer's discretization in the case of electro-spark deposited carbideceramic coatings modified by a laser beam. Solid State Phenom., 197, 198-202.

Radek, N., Konstanty, J., 2012. Cermet ESD coatings modified by laser treatment. Arch. Metall. Mater., 57(3), 665-670.

Radek, N., Pietraszek, J., Antoszewski, B., 2014. The average friction coefficient of laser textured surfaces of silicon carbide identified by RSM methodology. Adv. Mater. Res.-Switz., 874, 29-34.

Radek, N., Wajs, E., Luchka, M., 2008. The WC-Co electrospark alloying coatings modified by laser treatment. Powder Metall. Met. Ceram., 3-4, 197-201.

Singh, B. et al., 2017. Feasibility study for the measurement of pi $N$ transition distribution amplitudes at (P)over-barANDA in (P)over-barp $->\mathrm{J} /$ psi pi(0). Phys. Rev. D. 95, 3, 25 p., 032003.

Skrzypczak-Pietraszek, E., 2016. High production of flavonoids and phenolic acids for pharmaceutical purposes in Vitex agnus castus L. shoot culture. New Biotechnol., 33, 155.

Skrzypczak-Pietraszek, E., Kwiecien, I., Goldyn, A., Pietraszek, J., 2017. HPLC-DAD analysis of arbutin produced from hydroquinone in a biotransformation process in Origanum majorana L. shoot culture. Phytochem. Lett., 20, 443-448.

Skrzypczak-Pietraszek, E., Piska, K., Pietraszek, J., 2018. Enhanced production of the pharmaceutically important polyphenolic compounds in Vitex agnus castus $L$. shoot cultures by precursor feeding strategy. Eng. Life Sci., 18, 287-297.

Sygut, P., Klimecka-Tatar, D., Borkowski, S., 2016. Theoretical analysis of the influence of longitudinal stress changes on band dimensions during continuous rolling process. Arch. Metall. Mater., 61, 183-188.

Ulewicz, R., 2016. Quality Management System operation in the woodworking industry. Int. Conf. Path Forward for wood products: a global perspective. Proc. of Sci. Papers, Zagreb, WOODEMA, 51-56.

Ulewicz, R., Selejdak, J., Borkowski, S., Jagusiak-Kocik, M., 2013. Process management in the cast Iron foundry. Metal 2013: $22^{\text {nd }}$ Int. Conf. Metallurgy and Materials, Ostrava, Tanger, 1926-1931.

Ulewicz, R., Szataniak, P., Novy, F., 2014. Fatigue properties of wear resistant martensitic steel. Metal 2014: $23^{\text {rd }}$ Int. Conf. Metallurgy and Materials, Ostrava, Tanger, 784-789.

Weglowski, B., Osocha, P., 2009. Modelling of creep for $Y$ pipe from ferriticmartensitic P91 steel. Rynek Energii, 6, 140-145.

Wlodarczyk, R., Dudek, A., Nitkiewicz, Z., 2011. Corrosion analysis of sintered material used for low-temperature fuel cell plates. Arch. Metall. Mater., 56, 181186. 